\title{
Informal public transport in Sub-Saharan Africa as a vessel for Novel Intelligent Transport Systems
}

\author{
M.J. Booysen ${ }^{1}$, S.J. Andersen ${ }^{2}$, and A.S. Zeeman ${ }^{1}$
}

\begin{abstract}
Developed countries have lead the way in the implementation of Intelligent Transport Systems, with the objectives of improving safety, efficiency, and environmental impact of transport. With the developing world entering the fray, the questions are: Is ITS in its current form relevant to the developing world? These regions face challenges that are different to that of the developed world, and are unique in their own ways. Many of the regions are evolving novel and innovative solutions to deliver on ITS objectives. In this paper we explore the informal public transport sector in SubSaharan Africa, which is in many ways unique to that of the developing world. We highlight some of the unique aspects, and highlight the dire safety and efficiency challenges that the sector faces. Mindful of the regional limitations, we introduce and discuss novel ITS solutions, which can be used to address these challenges. We also share some of the initial results observed through initial experimentation with one of the solutions.
\end{abstract}

\section{INTRODUCTION}

Developed countries like the United States, Japan, and a number of countries in Europe, are leading the way in Intelligent Transportation Systems (ITS). Initially, these countries applied ITS for simple traffic control (e.g. traffic light coordination) and later Electronic Toll Collection (ETC), but it has since evolved to include electronic ticketing and automated fare collection, in-vehicle navigation and route guidance, real-time public transportation information distribution, monitoring and active control of traffic flow, and vehicular communications. The main drivers for ITS adoption are safety, efficiency, and environmental impact reduction.

To a large extent, every region decided on a different approach, and proprietary technologies were used. Since late 1980 's, most of the above countries developed national architectures to ensure a stable implementation environment. Furthermore, the ITS standards committee is quite active and ITS is addressed under the TC204 committee of ISO. The major role players across the globe participate in this committee.

Because of its dependence on wireless communications, electronic sensing, and computer-based data aggregation and visualization, successful deployment and maintenance of ITS is heavily dependent on advanced, and expensive technology and Information Technology (IT) [1].

\footnotetext{
${ }^{1}$ M.J. Booysen and A.S. Zeeman is with Department of Electrical and Electronic Engineering and smart travel lab, Stellenbosch University, Stellenbosch, South Africa. mjbooysen@sun.ac.za

${ }^{2}$ S.J. Andersen is with the Department of Civil Engineering and smart travel lab, Stellenbosch University, Stellenbosch, South Africa. , jandersenesun.ac.za
}

Developing regions in general, and Sub-Saharan Africa (SSA) in particular, have lagged behind in the implementation of ITS solutions, with the exeption of some cities in South Africa. These exceptions include

- Freeway Management System (FMS) projects in Gauteng, Cape Town, and Durban [2].

- Bus Rapid Transit programmes are rolled out in the major Metropoles, including Johannesburg, Cape Town, Tshwane, Durban, Rustenburg, Nelson Mandela Metropolitan Municipality, Buffalo city Municipality etc.

The focus of these exceptional systems is largely the provision of high quality pubic transport services, and has a large technology component to enable the improved focus on user satisfaction. These include fleet management systems, passenger information systems, surveillance on board and at stations to ensure passenger safety, electronic fare collection (cashless travel), etc.

Apart from these exceptions, the SSA region seriously lack guidance with regards to national ITS architecture. These countries are most vulnerable to ad-hoc deployments, technology/product dumping etc.

The solutions realised by ITS address the needs of the developing world as if tailor-made. To name a few, ITS implementations have the following benefits: improvement in traffic congestion (which directly improves productivity), improvement in efficiency and effectiveness of public transportation, help with transportation infrastructure management, prevention of accidents, improvement in emergency services, and reduction of emissions and global warming. The bleak reality is, however, that the developing world so desperately needs ITS, precisely because investment into infrastructure has been crippled by monetary constraints, mismanagement, and historical disadvantage - the same reasons it was wrong-footed by the digital divide, and the same barriers that might prevent successful ITS deployment.

An area with substantial potential for ITS implementation in the developing world is the informal public transport system in SSA. The advent of the taxi industry was in the late 1970s early 1980s - Little attention was given to the transport needs of the poor - hence the rise of the taxi industry, which was initially unregulated. Focus on ways to start regulating, based on demand per route as well as vehicle fitness, was started late 1980s. Many routes are regulated (permits provided), but driver behaviour remains big challenge.

The informal taxi industry has since sprawled into a vibrant industry. A recent study by the Trans-Africa con- 
TABLE I

DIFFERENCES BETWEEN PUBLIC TRANSPORT IN DEVELOPED COUNTRIES AND SUB-SAHARAN AFRICA.

\begin{tabular}{|c|c|c|c|}
\hline Aspect & $\begin{array}{l}\text { Developed world } \\
\text { Metered taxi }\end{array}$ & $\begin{array}{c}\text { Developed world } \\
\text { Bus } \\
\end{array}$ & $\begin{array}{l}\text { Sub-Saharan Africa } \\
\text { Minibus }\end{array}$ \\
\hline Payment type & Cash/card & Cash/card/free & Cash/ limited card use \\
\hline Payment event & After ride & Before ride & After middle of the journey \\
\hline Ownership & Private & Government or national industry & Many private owners \\
\hline Schedule & On demand & Predetermined, fixed, publicly available & Departs when full, peak times tacitly known \\
\hline Routes & On demand & Fixed & Partially fixed ${ }^{1}$ \\
\hline Vehicle & Small & Large & Small \\
\hline Number of passengers & Individual or small group & Many passengers & Many passengers \\
\hline Safety & Considered safe & Considered safe & Considered unsafe \\
\hline Stops & Taxi stops anywhere & Bus stops and designated stops on route & Taxi ranks, organically determined stops \\
\hline
\end{tabular}

sortium found Lagos alone had 80,000 informal minibuses. According to the Arrive Alive campaign, South Africa alone has more than 200,000 minibus taxis [3]. The story is similar for other countries in SSA, consider for example the ubiquitous Dala-Dalas in Tanzania, and Ndiaga Ndiaye from Senegal.

The African region has less than $2 \%$ of the worlds registered vehicles, but almost $20 \%$ of the global traffic deaths. According to the Trans-Africa study, the majority of taxi owners in SSA manage to cover their operation costs, but cannot afford to adequately maintain and upgrade their fleets, comprising on safety and quality. Both Senegal and South Africa have introduced fleet renewal programs, with varying levels of success [4].

\section{A. Contribution}

This paper explores one of the most prominent segments of transport in SSA, namely the informal public transportation industry. The informal public transportation industry performs a vital function in people mobility in SSA, and yet, little is known about this industry. The underlying mechanisms that drive this industry are explored, as well as the subtle differences between public transport in the developed world and the informal public transport industry. The unique challenges faced by the informal public transport industry are highlighted. Solutions that novel approaches to ITS could provide to address some of these challenges are explored, and results from initial experimentation are presented.

The rest of this paper is organized as follows: Section II provides an overview of the minibus taxi industry, explaining some of the subtleties that differentiate it from public transport in developed countries. Section III highlights some of the challenges that face the minibus taxi industry. Section IV explores how novel ITS implementations can be used to address these challenges. Section V concludes the paper.

\section{THE MINIBUS TAXI INDUSTRY}

This section provides an overview of the unique mechanisms at play in the minibus taxi industry to aid in understanding the challenges and opportunities for ITS implementations. The overview is especially significant because this informal industry operates on principles foreign to the developed world. Although the section focuses on South
African public transport, similar methods are in use in the rest of SSA.

There are five distinct role players that make up the informal transport industry, namely the owners, the drivers, the passengers, the taxi associations, and the regulation authorities. The drivers lease the vehicles from the owners, and have to earn a certain sub-minimum to make the business viable. The owners have very little control over the way their vehicles are used, and has no control over the flow of cash.

The taxi industry accounts for 65 percent of all public transport (14 million passengers) while buses and trains account for 21 and 14 percent respectively [5]. There are an estimated 20,000 taxi owners in South Africa, with a total of more than 200,000 taxis [6], [3]. The taxi industry employs around 185,000 people, mostly drivers. A taxi driver spends on average 8.8 hours per day on the road, and works an average of 6.33 days per week. This is 10 hours per week more than the average legal limit in the EU [7].

To make ends meet, especially on the longer routes during the festive seasons, some taxi drivers work 24 hour shifts, as detailed in section II-B. Due to the high number of fatalities in minibus taxis, a special maximum speed limit of 100 $\mathrm{km} / \mathrm{h}$ has been set for minibus taxis, $20 \mathrm{~km} / \mathrm{h}$ lower than the norm on highways, . The vehicle most commonly used as a minibus, the Toyota Quantum, is licensed to carry 14 sitting passengers. The average time a passenger spends in a taxi per day is 67 minutes.

The public informal transport industry of minibus transport in southern Africa can be divided into two functions, namely urban and long distance. The role that minibus taxis play in the urban transport network falls somewhere between that played by metered taxis (cabs) and urban buses in the developed world. The long-distance taxis perform a function akin to that of coaches in the developed world.

The key differences between the transportation modes in the developed world and those in SSA are listed in Table I. Even though the mechanisms and purpose of these two functions (long-distance and urban) are different, the vehicles and drivers are one and the same. It is not uncommon that a taxi driver, who ferried passengers to work and back from Monday morning to Friday afternoon, also complete a long distance route over the weekend. The long-distance trip typically departs at sunset on Friday night, returns before sunrise on Monday morning, and constitutes a combined $2400 \mathrm{~km}$. 


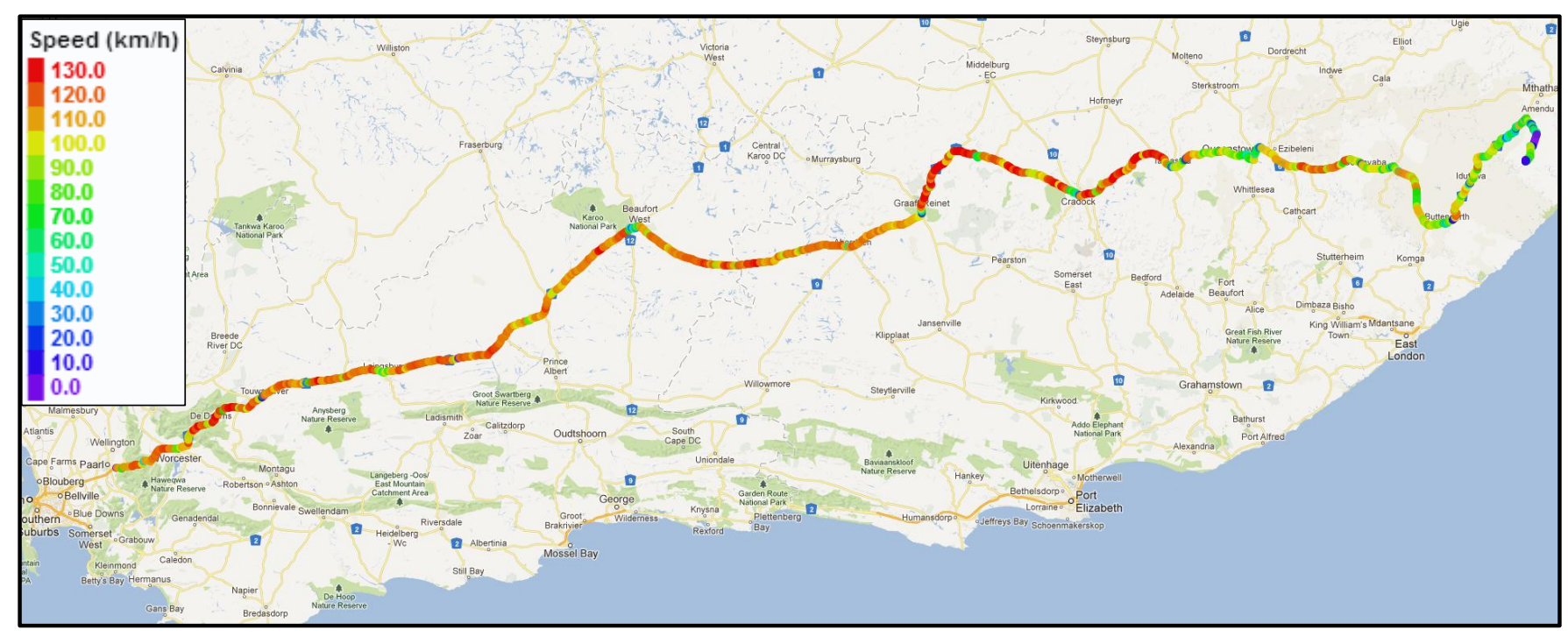

Fig. 1. Route of a long-distance taxi trip, with recorded speed in colour-coding. The trip is roughly $1200 \mathrm{~km}$.

\section{A. Urban transport}

In most cities but even rural areas, the taxi ranks (in some instances intermodal or modal transfer facilities) are formalised. There are clear origins and destinations, predetermined routes and permits allocated. There are typically rank marshals that try and keep some order at the rank. The journey for a minibus taxi in the urban scenario starts at the taxi rank with no passengers. The minibus falls in a queue of taxis that are heading in the same direction, roughly along the same route. When the taxi gets to the front of the queue, passengers can enter. Only when the taxi is full, does the driver depart. It is common for passengers to wait for another taxi to reach the front of the queue during peak time, for fear of getting into a taxi with a notoriously reckless driver. At peak times, this happens in a matter of minutes, but during non-peak times this could take hours.

The cost of a trip on the urban routes is fixed in agreement with the taxi associations. When the taxi is moving and a part of the journey completed, the passengers start to pay. Cash is passed on by the passengers from the paying passenger to the passenger next to the driver, who acts as the conductor, counts the change and passes it back to the paying passenger. In some instances a dedicated person is used to perform the functions of a conductor. This person manages the cash and is responsible to loudly persuade passers-by and pedestrians to use the taxi by shouting the destination.

When someone wants to get off along the route, they verbally indicate to the driver that they want to get out. The driver then stops at the most convenient location, and the passenger gets out. It is normal for a few people to get out of the vehicle to allow the disembarking passenger to get out. As soon as a seat in the taxi becomes available, other passengers that normally wait next to the road along the route, can be picked up. Passengers along the route will gather at tacitly known, unmarked points along the route., but a pick-up is not limited to these points. Passengers next to the road use pre-determined hand signals - indicating to the driver their required destination. If the taxi is heading in the same direction, the passengers will be picked up. Taxis typically show little respect for the law - will stop in the middle of an intersection, middle of the road, but hardly ever at pre-determined public transport stops. A short video of a trip in a taxi can be found in [8].

\section{B. Long-distance transport}

A typical long distance route of $1200 \mathrm{~km}$ from Cape Town to Mthatha, is shown in Fig 1. Long distance minibus taxis follow a different process to urban ones, although the same vehicles and drivers are used. A permit system exists for long-distance taxis. More permits are allocated for long weekends and the festive season. The passengers who want to go on a long-distance trip, typically for a funeral or to go home for the festive season, must pre-arrange a "contract" with one of the minibus owners. The cost of the contract is negotiable and includes delivery and collection at a specific destination. Many passengers therefore carry the telephone numbers of local taxi owners.

The taxi departs from a taxi rank and again waits until all the contracted passengers arrive. This $1200 \mathrm{~km}$ one-way trip normally starts on a Thursday or Friday evening around sunset, and the return trip finishes on a Monday morning before sunrise to allow passengers to start work on time. Although this system is completely organic, an interesting optimisation scheme has evolved: Unrelated taxis leave at around the same time, and then stop at about $50 \mathrm{~km}$ from the city. At this point passengers are swapped to optimise the routes the taxis will take. Another, more concerning oddity of the long-distance trips is that the driver hands over control of the vehicle to a willing passenger when he inevitably suffers from fatigue during the trip. This passenger is not necessarily licensed to drive the vehicle, and may not even have experience in doing so. 
In summary, SSA's taxis are much more demand driven and organic with more discretion, but also with more uncertainty.

\section{Challenges AND ISSUES IN INFORMAL PUblic TRANSPORTATION IN SSA}

This section will highlight some of the key challenges that face the informal public transport industry in Sub-Saharan Africa.

\section{A. SSA regional}

Implementation of ITS solutions from the developed world are not always feasible in developing countries. Some of the main reasons for this are

- Cost of implementation

- Cost of maintenance and operations

- Intermittent supply of electricity

- Lack of technical skills in country

- Remote roads and distance to cities.

This paper focuses on the informal public transport industry in SSA, rather than the developing world in general. In stark contrast to the main objectives of ITS, namely improvement of safety and efficiency, the main challenges to the informal transportation industry are safety and efficiency. Each of these challenges are discussed below.

\section{B. Safety}

Despite being considered as a safe alternative in the developed world, public transport is considered to be a dangerous option in SSA. This fact is best illustrated by the numerous night vigils that are held by would-be passengers the night before a long-distance journey, but also substantiated by the high number of fatal taxi accidents. The root cause for the unsafe nature of this form of travel can be found in the financial incentives and lack of policing. The drivers have a clear incentive to generate as much money as possible, which can be done by accommodating more passengers per trip, or by completing more trips. The taxis are therefore overloaded, or the drivers speed and perform dangerous stunts between destinations, both of which lead to dangerous driving conditions.

Often, the owners are not in a financial position to adequately maintain their vehicles and keep them road worthy. This problem is compounded by the owners not having control over the way the vehicles are driven. Authorities also do not have the capacity to effectively police compliance to legislation relating to driving speed, occupancy (overloading), and responsible driving. Moreover, they long-distance taxis travel after hours, when policing is reduced.

\section{Efficiency}

The processes described in section II demonstrate that despite the organic optimisations that has evolved in the industry, various inefficiencies are still apparent. The biggest inefficiency is the time that is spent waiting, by both the passengers as well as the drivers. The waiting forms part of both the urban and long-distance taxi service. In the former
TABLE II

SPEEDS FOR THE TWO DIRECTIONS OF A WEEKEND JOURNEY. NUMBER OF SAMPLES ABOVE THRESHOLD.

\begin{tabular}{|c|c|c|}
\hline Threshold & To the Eastern Cape & Return to Cape Town \\
\hline$>100$ & $48 \%$ & $59 \%$ \\
$>110$ & $27 \%$ & $44 \%$ \\
$>120$ & $3 \%$ & $13 \%$ \\
$>130$ & $0 \%$ & $4 \%$ \\
$>140$ & $0 \%$ & $1 \%$ \\
Number of samples & 1586 & 1424 \\
\hline
\end{tabular}

people have to wait for the taxi to fill. In the latter, people wait at allocated points for the contracted passenger to turn up.

\section{ITS SUPPORT FOR INFORMAL PUBLIC TRANSPORTATION IN SSA}

It is evident from the preceding sections that, to fully embrace the unique challenges and opportunities of ITS in the developing world, one almost has to unlearn what ITS means in the developing world. This section will explore some of the opportunities to apply ITS in the informal public transport industry.

\section{A. SSA regional}

Despite the financial challenges, being on the wrong side of the digital divide provides an opportunity for SSA to leapfrog some of the ITS technical development phases, especially the wireless communications technologies. If the decision makers are therefore empowered and knowledgeable, they could avoid many of the mistakes made, and unnecessary expenses incurred, during initial implementation in the developed countries. An interesting option is to move away from standards specifically developed for ITS, and instead use existing cellular communications such as or Third generation (3G), WiMAX, and Long Term Evolution (LTE). The data rates of modern cellular networks can support a large number of the applications foreseen for ITS, including Vehicle to Infrastructure (V2I) communications. In V2I communications vehicles, as opposed to the passengers in it, communicate with the ITS in a Machine-to-Machine (M2M) configuration.

Due to the high level of vehicle theft in South Africa, tracking devices used for vehicle-recovery are very popular. Tracker, one of the many tracking service providers, have in excess of 250,000 tracking devices installed, with over 10,000 new installations per month [9].

\section{B. Safety}

An opportunity that the use of tracking devices enable, is the ability to monitor driving behaviour. Many of the modern tracking devices also capture acceleration and angular velocity in addition to speed and location. The acceleration and and angular velocity can be used to monitor driver behaviour, which is especially useful in the informal public transport scenario. Models to specifically monitor minibus taxi driver behaviour using tracking devices are developed in [10] and can be used to alert the authorities of speed limit violations 


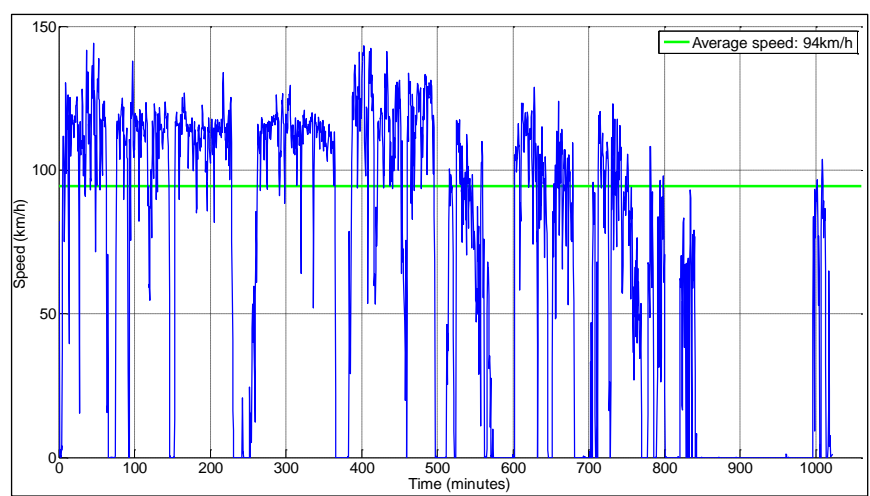

Fig. 2. Speed profile for a one-way trip.

in real-time. Our preliminary experiments, in which we have tracked actual taxis, have shown that the speed limit of 100 $\mathrm{km} / \mathrm{h}$ is almost completely ignored. A graph of the speeds of one of the trips is shown in Fig. 2, clearly showing the speeds exceeding the legal limit of $100 \mathrm{~km} / \mathrm{hr}$. The speed data, also presented in Fig. 1 provides an easy way for traffic management agencies to strategically position speed enforcement, rather than the currently employed open-ended approach. The preliminary results also seem to indicate that the speed profile to the destination is substantially different to that of the return journey. This is clearly shown through the results in Tab. II. We believe the reason is the impending deadline for the return, as well as the late departure due to the number of collection points.

The occupancy detection system developed in [11] could also be expanded upon to monitor for passenger-overloading of minibus taxis.

\section{Efficiency}

An unintended consequence of the tracker penetration is that the tracking devices, which have cellular connectivity, can be leveraged to provide very accurate traffic flow information, where a high ratio of vehicles serve as active probes. It is important to note that this solution is not a panacea though, since it does not provide information on the traffic volumes. This is in contrast to the traditional stationary road-based loops in use in ITSs in developed countries. The tracking companies sell their real-time vehicle location and speed properties to other entities, such as tomtom and Google, that use the information in up-to-date route calculations.

Another use for the tracking devices is to improve understanding of the hereto undocumented trips. For example, our preliminary experiments have shown the following:

- Actual departure times of the tracked taxis

- Trip duration, which is close to $10 \%$ longer to the destination than the trip back to the origin. We believe the reason is the impending deadline for the return, as well as the late departure due to the number of collection points.

- Routes taken and most common drop-off points
- Typical times for passing certain towns and points of interest.

- Where and when the drivers take a break and which filling stations are frequented. We have found that only two refreshment stops are made during each trip of 11 to 12 hours. .

All of this information is undocumented as far as we know.

One of the mandates of government is to regulate the taxi industry and to understand how many people are being transported on which routes. This information is then used for road planning and investment in infrastructure. Given the informal nature of the taxi industry in SSA, government agencies struggle to capture the travel patterns and loads carried. To better understand the number of people being transported by this industry, the work in [11] presents a cost effective solution to perform real-time occupancy detection using capacitive seat sensors in a connected vehicle.

Given the large penetration of cellular networks in the developing world, the cost of investment in ITS infrastructure could be substantially less than a traditional ITS implementation. An evolution to using cellular networks in ITS would, for example, mean that instead of using the traditional road-based traffic sensors (loops and radar), vehicles with a smartphone or cellular tracking device, could be used as a probe to measure traffic flow significantly reducing the financial and maintenance burden on road agencies. Moreover, knowledge gained from the installation of cellular networks could be leveraged for ITS installations and applications. When one considers the cellular coverage maps of countries like Botswana, Nigeria, Zambia, or Kenya, it is clear that cellular coverage is most predominant in the large cities and along the main roads, which exactly where one would need vehicular connectivity and other ITS services [12]. An example of such a system where mobile phones are used in a collaborative effort to improve traffic, called ITSPhone, is described in [13]

The work done in [14] demonstrates how collaborative sharing can be used to optimize parking allocation in the developed world. This approach can easily be converted and applied to the informal public transport system in SSA, where people could compete and allocate seats on minibus taxis. The system can also be used to ensure that passengers can reserve a safe and trusted driver.

\section{Augmented services}

Apart from the services that support typical ITS solutions, some peripheral services can be implemented which can serve as a financial incentive for the owners and drivers to support the ITS initiatives.

Since the passengers in a taxi are captive on average for 67 minutes per day in the urban taxis, and for up to 12 hours for the one-way long-distance journey, a potential exists to provide location based services as well as advertisement platforms in the taxi. The work in [4]] presents a proof of concept platform in the city in Cape Town, where cashfree card-based payment systems were integrated into 40 taxis. To augment the ITS functionality, live advertising 
platforms (LCD screens) were incorporated, which allows location based information dissemination as well as onscreen advertising.

An interesting aspect to Information and Communications Technology (ICT) in SSA, is the cost of telecommunications (transport of information) as opposed to the cost of roadbased transportation. If one had to transmit information from Cape Town to Johannesburg $(1300 \mathrm{~km})$, it is more costeffective to use a pick-up truck filled with DVDs than to use existing telecommunication technologies to transfer the same amount of data. Since minibus taxis service almost all populous areas, this opens new opportunities to use the taxis as data couriers, especially to the rural areas, which tend to not have adequate connectivity.

\section{CONCLUSion}

The informal public transport industry of Sub-Saharan Africa is described in detail. The features that make this industry unique are described as well as the processes that operate in the urban and long-distance manifestations of the industry. Some of the key safety and efficiency challenges facing the industry are analysed and described. In the context of Sub-Saharan Africa, novel solutions are proposed and discussed to address these challenges, which tend to move away from the typical road-based solutions to a vehicle- and person-based approach. The results of preliminary tracking experiments are provided, clearly showing firstly recklessness of the drivers, and also the potential of the proposed solutions. If trackers could be legislated, policing would become much easier, which should save many lives. The information captured could also be used to significantly save on waiting times.

\section{ACKNOWLEDGEMENT}

The authors would like to acknowledge Trinity Telecoms for their support and access to the SMART M2M-enabling and visualization platform.

\section{REFERENCES}

[1] M. J. Booysen, J. S. Gilmore, S. Zeadally, and G.-J. van Rooyen, "Machine-to-machine ( $\mathrm{m} 2 \mathrm{~m})$ communications in vehicular networks," TIIS, vol. 6, no. 2, pp. 529-546, 2012.

[2] SANRAL, "Gauteng freeway improvement project," http://www.nra.co.za/live/content.php?Category_ID=58.

[3] Arrive Alive campaign, "Minibus taxis and road safety," http://www.arrivealive.co.za/pages.aspx?i=2850.

[4] Koos van Zyl and Jonathan Myers, "Introducing its in unsibsidised public transport." in 12th Conference on Competition and ownership in land passenger transport. Durban, South Africa, September 2011.

[5] Transport Education Training Authority, "Overview," http://www.teta.org.za/Chambers/Taxi/overview.shtml.

[6] Mercatus, "Taxing alternatives: Poverty alleviation and the south african taxi/minibus industry," http://mercatus.org/sites/default/files/publication/Taxi_Policy_Series.pdf.

[7] UK Drivers, "Bus drivers' eu hours rules," www.ukdrivers.com/bus_hours.asp.

[8] A.S. Zeeman, "Video of a trip in an urban taxi." http://goo.gl/X8FP0.

[9] Tracker, "Why tracker," http://tracker.co.za.

[10] A.S. Zeeman, and M.J. Booysen, "Acceleration-speed model for minibus taxis to recognise and report erratic driving." Subitted to IEEE-ITCS 2013, copy available at http://goo.gl/jor7z.
[11] A. Zeeman and M. J. Booysen, "Capacitive seat sensors for multiple occupancy detection using a low-cost setup," in IEEE International Conference on Industrial Technologies (ICIT), April 2013.

[12] M.J. Booysen, "Relevance of intelligent transportation systems (its) in sub-saharan africa." in Fully Networked Car conference at the Geneva International Motor show, hosted by ISO, IEC, and ITU., March 2012.

[13] O. Briante et al., "Itsphone: an integrated platform for participatory its data collection and opportunistic transfer." in IEEE International Conference on Computer Communications (InfoCOM), February 2013.

[14] T. Delot, S. Ilarri, S. Lecomte, and N. Cenerario, "Sharing with caution: Managing parking spaces in vehicular networks," Mobile Information Systems, vol. 9, no. 1, pp. 69-98, 2013. 